\title{
Social Control Theory Variables in Conceptualizing Bonding Models of Attachment Theory and Adolescent Development
}

\author{
Mehmet Aslan \\ Vikinta Rosinaite \\ Lasha Khojanashvili \\ Liberal Arts, \\ American University of the Middle East, \\ Kuwait/Kuwait
}

Doi: 10.2478/ajis-2019-0031

\begin{abstract}
The developmental models on positive relations between youth and educational settings have increasingly been areas of interest for researchers, educators and developmental psychologists indicating that to have each and every individual ready to learn and instructors motivated to teach; academic achievement and psychological well-being of youth require an approach of bonding model in education for today's diverse learner needs. In this regard, vigorous research together with a robust theoretical base provided by Attachment Theory was investigated as basis of the present study in obtaining an in depth analysis of healthy process of School Psychology for practitioners, psychologists and counselors through a focus on theoretical framework of Social Control Theory. Such an approach would not only help to develop a profound look into the betterment of educational and psychological services but also provide an essential insight into predictors for strong, healthy, academic development of adolescents. Present study, primarily aims at providing Theoretical Framework of Bonding Models through analysis of Social Control Theory as to conceptualize adolescents' experiences and their attachment levels in order to prevent the risks of delinquent behavior with four major variables; attachment, commitment, involvement and belief. The study also focused on how these variables helped building bonding models of attachment in regard of its relation with fundamentals of attachment theory and its development into new directions.
\end{abstract}

Keywords: Bonding models, development, social control theory, attachment, commitment, involvement and belief

\section{Introduction}

Attachment as a concept in regard with Bonding Models goes along with many other names such as; connectedness, bonding, engagement, belonging etc. however as a theory, it derives its roots from John Bowlby, the founder of the theory and Mary Ainsworth, the developer and co-founder of the theory who also brought up a new face to it. They both have deep conceptualization of attachment with a similarity seen on both psychologists and can be considered co-workers in creating the theory; they thought of attachment as a deep long-lasting emotional connectedness that bonds one individual to another that is beyond space and time (M. Ainsworth, 1973; Bowlby, 1969).

Attachment primarily, not only as a theory but also as a pioneering model, has been developed throughout John Bowlby`s lifespan. It basically studies the development of unique and strong fondness between a child and its parent through which the child seeks comfort and security 
from the parent or caregiver. Since parent is the first person encountered by the child, the theory is about the first experienced relationship and its impact on child's whole life. This first attachment experience has impact on all other later developed relations as it teaches the child about how to develop trust on others for support and maintenance. The senses of belief, self-esteem, and efficacy are also influenced as they learn how to rely on other people. At this point, it is worth to mention the significance of secure attachment, because it promotes dependence and independence - the abilities of relying on the others and the self - at the same time. Together with birth children need to have a primary caregiver, so they can feel safe and secure. Substitution of the primary caregiver with another accustomed adult can also happen for temporary moments through which the secondary attachment occurs (Bowlby, 1960a). The senses of security, belief, safety etc. encourage the child to further explore the surroundings, especially through play which also helps the child to experience other feelings like; stranger anxiety, worry, fear etc. during when the need for comfort arises. It is important that the child finds close, physical contact from primary or secondary attachment figure in such cases. The physical comfort may turn into verbal or some other formats as they grow up (Bowlby, 1958).

\subsection{New Directions of Attachment Theory}

Although attachment has been highly valued in regard with infant-mother relations, due to confusions on attachment bond and trauma bond there have been fatal mistakes as well. Death of Baby $\mathrm{P}$ in England in 2007 as a criminal case due to beatings and parental abuse underscored a fatal misconception of attachment theory, because the theory centralizes human safety first than emphasizes the significance of infant-mother relation. Schwartz (2015) gives a detailed table on differences between attachment bond and trauma bond: "An attachment bond makes the infant safe and is the basis of Winnicott's facilitating environment. The trauma bond is not safe. It is a desperate exercise in self-preservation" (Schwartz, 2015, p. 258). Particularly, in clinical work, Slade mentions that "Attachment theory informs but does not determine clinical work" (Slade, 1999). It is internationally regarded as a frame of reference in treating trauma (Arikan \& Karanci, 2012; Zurbriggen et al., 2012).

\subsection{Social Control Theory}

Hirschi (1969) investigated the roots of misconducted behaviors and tried to understand the causes behind such behaviors. The triggering question he asked himself was why most of the people were adhering to rules and not getting involved with misconducts, and why the other small scale of individuals were getting involved with delinquency. He, thus established his concept of social bonding by explaining the elements of bonding like family, peers, community, school etc. as causes for preventing or limiting misconducts. The theory suggests that people with strong social bonds are more likely to avoid misconducts as they would obey and accept social rules more easily, however the ones with weak bonds would show more tendency in breaking the rules (Booth et al., 2008; Hirschi, 1969) which shows parallel indications with school attachment (SA) as current study aims to demonstrate through Social Contro Theory (SCT) variables.

\section{Methodology}

The main purpose of the study was to analyze the four SCT variables; attachment, commitment, involvement and belief that foster attachment (SA) levels of adolescents by not only buffering the delinquent behaviors but also helping researchers conceptualize bonding models of attachment theory with its new directions. In this regard, an in-depth analysis of SCT variables, attachment theory together with its original founders were investigated through secondary data as well as a table that was created on Attachment Theory and Its Development Process by Author, Content and Contribution to the Field (See Literature Review). 


\section{Literature Review}

Although Bowlby and Ainsworth are two independent psychologists, their approaches may indicate some controversial influences of Freud, especially on his thoughts of psychoanalysis as well as ethology, developmental psychology, automation, cognitive development etc. In this regard, Freud's thoughts on development are worth to quote to see the origins of attachment: "So long as we trace the development from its final outcome backwards, the chain of events appears continuous, and we feel we have gained an insight which is completely satisfactory or even exhaustive" (Freud, 1920, p. 167). After all, the opinions and perceptions we have gained today on attachment theory have a deep developmental background. Bowlby mainly composed his theory through following works; "The Nature of the Child's Tie to His Mother" (1958), "Separation Anxiety" (1960b), "Grief and Mourning in Infancy and Early Childhood" (1960a) and "Attachment and Loss Vol. I and II" following the years of 1973 and 1982. Mary Ainsworth also studied the same theory and formulized her innovational attachment patterns through following major works; "Child Care and the Growth of Love" (1965), "Infancy in Uganda: Infant Care and the Growth of Love." (1967), and "Patterns of Attachment" (1964)

\subsection{Social Control Theory And Bonding Models}

Social Control Theory founded by Hirschi (1969) has been supplementing significant intuitiveness, in particular for the reasons behind delinquent behavior. In this regard grading rules and regional background could be considered together with students' interaction with societal affairs as two significant variables that could be implemented in surveys or research to conceptualize high school students' school life experiences and their SA levels. Studies conducted on society or its organizations like schools brought up the eventual question of how order can be achieved on social interactions. This question begged for the question of how we can eliminate delinquent behavior, through which Hirschi (1969) proposed SCT and he suggested that the societal control has impact in redeeming or diminishing misconducted behavior. SCT is basically built on four variables; Attachment, Commitment, Involvement, and Belief; however these variables were used in different studies with different measurement scales and with additions or extractions. The present study also derived its variables from SCT with some differences, yet implementing the same logic of the theory in conceptualizing high school students' interactions with schools as a societal organization that have control over them in eliminating delinquent behavior.

Social Control as a phrase has long been used in academic studies, even years before Hirschi wrote his book "Causes of Delinquency" in 1969 which later on became a model for further research: "Early research in social control focused on the development of inventories of societal means of social control" (Wiatrowski, Griswold, \& Roberts, 1981, p. 2), nevertheless this approach was left behind due to new approaches developed by scholars. The new model developed by Hirschi is more focused on delinquent behavior and its relation with social lives of different groups or organizations like schools. He suggested that since early ages of childhood, individuals either develop healthy bonds to society they live in and avoid delinquent behavior or fail to form a healthy bondlattachment with the society slhe lives in and happen to be delinquent: "Hirschi's theory was strongly supported by the research he conducted which showed that delinquency involvement was inversely related to the strength of an individual's relationship to society" (Wiatrowski et al., 1981, pp. 2-3). According to SCT, adolescents achieve levels of socializing with variant experiences that help them change and adapt that also occur through school life which are related with their backgrounds as well. The changes or skills gained have impact on individuals` involvement or non-involvement into delinquent behaviors.

\section{Conceptualizing the Framework of School Bonding Model}

SA as a developmental framework needs to be defined together with SCT (Social Control Theory) which was first established by Hirschi (1969) to measure student's school attachments. SA model aimed at presenting a better understanding of the framework and establish particular variables in 
measuring SA in regard with social bonding. Within the following headings an overview of the SCT is presented, then its relation with $\mathrm{SA}$ is established to conceptualize its significance and assistance in building the SA measurement scales, and finally SA is studied with its intrinsic and extrinsic structures and its relations with other variables of theoretical frameworks.

Researchers have been trying to apply attachment into several fronts; some of them are; therapy, all types of relations (particularly couples), throughout lifespan, developmental psychology, industrial-organizational psychology (in regard with employer, employee, work and workplace), adolescence development, SA etc. The theory is still emerging among psychoanalysts, psychologists, and scholars in general. There is a long growing history of conceptions that find their origins in theories of attachment. Each and every development has been contributing to its maturation and expansion (see the table below).

Table 1: Summary of Theoretical Framework of Attachment Theory and Its Development Process by Author, Content and Contribution to the Field

\begin{tabular}{|c|c|}
\hline Author & Content of the Study \\
\hline $\begin{array}{l}\text { Freud, S. } \\
\text { (1955) }\end{array}$ & $\begin{array}{l}\text {-The psychogenesis of a case of homosexuality in a } \\
\text { woman. In } 3 \text {. Strachey (Ed.and Trans.) }\end{array}$ \\
\hline $\begin{array}{l}\text { Bowlby, J. } \\
(1940,1944, \\
1958,1960,1969, \\
1973,1982 .)\end{array}$ & $\begin{array}{l}\text { - The influence of early environment in the development of } \\
\text { neurosis and neu-rotic character } \\
\text { - Forty-four juvenile thieves: Their characters and home } \\
\text { lives }\end{array}$ \\
\hline & $\begin{array}{l}\text { - The nature of the child's tie to his mother } \\
\text { - Grief and mourning in infancy and early childhood } \\
\text { - Attachment. Attachment and Loss: Vol. 1. Loss. } \\
\text { - Infants and mothers: Differences in development } \\
\text { - Attachment and loss (vol. 2), Separation: Anxiety and } \\
\text { anger } \\
\text { - Attachment and loss: Vol. } 1 \text { second edition. Attachment. }\end{array}$ \\
\hline $\begin{array}{l}\text { Ainsworth, M. S. } \\
(1965,1967, \\
1969,1973,1978\end{array}$ & $\begin{array}{l}\text { - Child care and the growth of love. } \\
\text { - Infancy in Uganda: Infant care and the growth of love, } \\
\text { Baltimore }\end{array}$ \\
\hline 1979) & $\begin{array}{l}\text { - Object Relations, Dependency, and Attachment: A } \\
\text { Theoretical Review of the Infant-Mother Relationship } \\
\text { - The development of infant-mother attachment } \\
\text { - Patterns of attachment: A } \\
\text { psychological study of the Strange Situation } \\
\text { - Infant-mother attachment }\end{array}$ \\
\hline
\end{tabular}

Main and

Solomon,

(1986)

Schaffer \&

Emerson,

(1964)

Heinicke \&

Westheimer

(1966)

Ambrose, J. A.

(1961)

Brazelton, $\mathrm{T}$.

Berry

(1969, 1992)

Klaus \& Kennell

(1976)

Sroufe, L. A.

(1983)

Schwartz, J.

(2015)

Slade, A.

(2006)

Arikan \& Karanci (2012)

-Discovery of a New,Insecure-Disorganized/Disoriented Attachment Pattern

-The development of social attachments in infancy

- Brief separations

- The development of the smiling response in early human infancy

- Infants and mothers: Differences in development

- Touchpoints. Child's Emotional and Behavioral

Development loss on family development

- Infant-caregiver attachment and patterns of adaptation in preschool: : The roots of maladaptation and competence

- The Unacknowledged History of John Bowlby's Attachment Theory

- Attachment Theory and Research: Implications for the

Theory and Practice of Individual Psychotherapy with Adults

- Attachment and coping as facilitators of posttraumatic growth in Turkish university students experiencing
Contribution to the Field

influences of Freud on Bowlby, especially on his thoughts of psychoanalysis

Attachment primarily, not only as a theory but also as a pioneering model, has been developed throughout John Bowlby`s lifespan. It basically studies the development of unique and strong fondness between a child and its parent through which the child seeks comfort and security from the parent.

Ainsworth same as Bowlby, believed that human circumstances could be enhanced through psychology and profound research. They were both interested in maternal deprivation, but Ainsworth went beyond that to study infant development, especially in regard with security aspects. Ainsworth reached following results also known as three basic attachment patterns;

Secure Attachment

Anxious-Ambivalent insecure attachment

Anxious-Avoidant insecure attachment

Discovery of a New, Insecure-

Disorganized/Disoriented Attachment Pattern

Monographs of the Society for Research in Child Development

Extra reunion and separation researches

- Maternal-infant bonding: The impact of early separation or traumatic events
An experimental and theoretical study of their course and significance.

Brought the theory to today`s modern understanding. Implemented studies on early infancy.

They worked for many years and brought up the concept of bonding together with attachment as bonding occurs from parent to infant and attachment occurs from infant to parent.

The Minnesota study, outlined by Alan Sroufe was one of the major longitudinal studies on the relationship between secure attachment and caregiving quality. detailed information on differences between attachment bond and trauma bond Set differences between attachment theory and clinical work.

Used Salde's opinion as a frame of reference in treating trauma. 


\subsection{Theoretical Constructs of Social Bonding Factors}

According to Social Control Theory there are four aspects of bonding; Attachment, Commitment, Involvement and Belief.

\subsubsection{Attachment}

According to SCT attachment is based on the bond between the person and societal group within which the individual lives in and also involves person's private relations with immediate surroundings of close people like; peers, instructors, parents etc. The quality of interactions between teachers, students and peers are the main focus areas of attachment. For peers, the relationship built between friends and its level of quality; if the student is able to adapt with peers, if the student has delinquency issues etc. are concern areas; for teachers attachment involves student's perception of the teacher, closeness, the impacts of reinforcements on the student etc. are concern areas.

Divergence from socially shared norms causes delinquencies or misconducted behavior. He defined delinquency as; "to act contrary to the wishes and expectations of other people" (Hirschi, 1969 , p. 18). A person's positive senses and caring for people around is the source for responding their expectations and wishes, thus he suggested that close relations with other people make the individual obey their rules, values, expectations, norms etc. The theory basically hypotheses that a person that builds stronger bonds with people around is more likely to care and show loyalty to their values, norms etc. and consequently would be more bonded to customary ways of behaviors (Booth et al., 2008; Hirschi, 2002).

\subsubsection{Commitment}

The interception of school services with students' needs in achieving targeted goals which also ordains students' perception of school, homework, extracurricular activities etc. indicate the quality of students' commitment. The students ' perception is based on the quality of the facilities, services and activities which would eventually help them to achieve success, contentment, and satisfaction, if the school environment is well suited for such goals then the student would develop healthy relations with school and feel more committed with school activities. The logical assumptions of consequences when delinquent behavior is conducted and their impact on the person are also what reflect commitment. When the individual holds on the side of "stakes in conformity" (Hirschi, 1969, p. 152), the person would have made a choice between consent and deviation from the customary ways of acting thus would spend energy in getting better education, staying away from substances, hardworking etc. The commitment is expected for the rules and values of communal group the person lives within. However, if the commitment scales to conformity are low, the individual is more likely to indicate misconducted behavior and show deviation from customary rules or values of social group (Booth et al., 2008; Hirschi, 2002).

Commitment in regard with school overall evaluates student's individual endowment to school which is consequently seen through his/her behaviors and beliefs. When student makes such an endowment he/she also puts forth the trust in the importance and value of grading system as he/she also believes that engaging with school activities and displaying some particular behaviors are needed for achieving better performance as in doing homework, bringing school materials from home etc. (Libbey, 2004). Studies of school commitment indicate that students that are with high scales of engagement with school activities due to commitment investments and do their tasks with commitment senses are reported to be with overall higher performances and lower delinquency behaviors (Sciarra \& Seirup, 2008; Stewart, 2007).

\subsubsection{Involvement}

The contentment feelings from school life and overall experiences with conventional and nonconventional school activities are indicators to show the level of student's involvement. In this 
regard, student-school interactions are based on customary or non-customary experiences of extracurricular activities which are defined by SCT to reflect students' outcome as well. The effort and time used in customary actions and its scale defines its strength and weakness. The idea is basically based on individual's engagement with expected behaviors so that there wouldn't be time for any other misconducted behavior. If a person is left alone without any engagement he or she would end up with a deviant activity, thus the theory hypothesizes that the person should be preoccupied with expected, desired activities like educative activities, trainings etc. so as to stop ways of delinquency (Booth et al., 2008; Hirschi, 2002).

Involvement in regard with school overall is described through students participations to school activities, in particular to after school activities which includes diverse types of extracurricular activities that make students display some certain behavioral patterns (Maddox \& Prinz, 2003) through which favorable outcomes and interactions occur that create relations between displayed behaviors of students 'participations to activities and school performance as well as performance related consequences (Dumais, 2008, 2009; J. A. Fredricks \& Eccles, 2008; Zaff, Moore, Papillo, \& Williams, 2003). The relation between extracurricular activities and school involvement shows that such engagements as well as doing homework etc. has positive impact on school attachment.

\subsubsection{Belief}

The rules, values shared within communal group are measured with members' belief in them and their validness, reliance etc. are what determines an individual's belief. The theory suggests that if an individual has strong senses of belief, the scales of delinquent behavior would be low accordingly as they have strong correlation with each other (Booth et al., 2008; Hirschi, 2002). The students basically accept and internalize school regulations and their applications by admin staff and teachers as fair and rightful.

\subsection{Relationship between Bonding Factors}

SCT suggests that all four bonding components are correlated with one another in a positive way, moreover it was mentioned that there wasn't characteristic of a ranked order as one component could not be superior or inferior to the other: "the more closely a person is tied to conventional society in any of these ways, the more closely he [she] is likely to be tied in the other ways" (Hirschi, 1969, p. 27).

\subsection{Validity of the Social Control Theory}

Researchers mostly had been concentrated on youth delinquency in regard with occurrence and prediction of misconducted behavior in measuring SCT's validity. Previously conducted research majorly established that delinquency of social bonds occurred at the same time with adolescent's eluding of misconducted behavior as well as reported delinquent behavior (Huebner \& Betts, 2002), occurring at the same time with relinquishing from crime and development (Bushway, Piquero, Broidy, Cauffman, \& Mazerolle, 2001), and its impact on school performance due to delinquency in bonds. Some other researchers criticized methodology of previous studies as they were based on cross sectional data driven from the relation of delinquency and bonds. Consequently, studies approve the validity and usefulness of SCT as it had given a conceptualized framework by establishing the relation between a person and socially developed organizations and the impact of this relation on person`s manners (Booth et al., 2008).

\subsection{Social Control Theory as a Framework for Conceptualizing Attachment}

Previously implemented studies were mostly attempted on conceptualization and measurement of SA through SCT (Battistich \& Hom, 1997; Brown \& Evans, 2002; Cho, Hallfors, \& Sánchez, 2005; Loukas, Roalson, \& Herrera, 2010; O'Farrell \& Morrison, 2003; Resnick et al., 1997). Previous studies were compared to the innovative work of Hirschi (2002) by O'Farrell and Morrison (2003) 
through a meta-review and components of SA found to be similar with Hirschi's (2002) social bonding components.

The SCT plays a significant role in understanding and scaling the relation between a person and the social group the person lives in. The usefulness of the social norms and values, individual's comprehension of them, the effort and time spent with the them, reliability and validity of them, individuals interactions within the social groups are what the SCT involves as a theory. This approach with variant aspects and variables also help studies to analyze and investigate student's interrelations with schools as social organizations.

SCT together with Social Development Theory (SDT) has been regarded as one of the key foundations in conceptualization of SA, in particular when it's held with Attachment Theory (Catalano \& Hawkins, 1996). The three founded theories are interconnected: Attachment theory plays the core role and helps with the infrastructure of SCT. SDT, on the other hand is very much related with adolescent development within social organizations and it's a derivation of SCT to measure youth learning skills.

Attachment Theory is basically about individual's feelings of reliance on important other people that provide conform, belief, norms, values etc. depending on how secure was the attachment developed. This concept also helped foundation of SCT as Hirschi (1969) used "prolonged separation" to define "deprivation" and to explain socially weakened bonds (Hirschi, 1969, p. 86).

Nonetheless the relationship between the individual and organizations, person's comprehension of facilities, reliance on admin staff, contentment with services etc. are not directly addressed by Attachment Theory. In this regard, SCT plays a core role in focusing on interpersonal and intrapersonal relations, especially between the individual and organization, in particular conceptualizing SA and social organizations. Likewise, SDT and Social Learning Theory (SLT) are sub-structures of SCT. Development of social bonds through which adjustment of behaviors occur is considered by Catalano and Hawkins et al. (2001) as transformation of behaviors, gaining of socially adaptive attitudes and child's social development, because the individual goes through communal settings like schools. Moreover, the expected behaviors and delinquent behaviors are considered separately by these theories.

\section{Conclusion}

SDT different than SCT is more focused on positive and negative reinforcement of the behavior in order to obtain expected, conventional behavior and avoid delinquent behaviors. In this regard, having desired and unwanted behavior separately studied would contribute to accurate predictions of students' future and present delinquencies. Since SCT is mostly focused on measurement of SA and its conceptualization, SDT could be a good contributor to SCT in obtaining better measurement instruments and variables. The theories, however, both give importance to student-teacher relations, peer attitudes, engagement, contentment with school services, time spent for extracurricular activities etc. (Hawkins et al., 2001; Williams, Ayers, Abbott, Hawkins, \& Catalano, 1999).

SCT's model, built on four variables; attachment, commitment, involvement, and belief so far has been the best approach in conceptualizing students' interactions with school as it gives a direct insight to the reciprocal relationship between student and school as a mileu. The framework constructed by this model not only provided a measurement instrument but also helped researchers to empirically comprehend and conceptualize this relationship. This model based on four variables can be applied to SA studies with some additions or extractions as well. The characteristics of individuals and the environment they live in can be studied by application of SCT model as it provides an interaction based framework for social organizations like schools, peer units, family, student-teacher interactions etc. 


\section{References}

Ainsworth, M. D. (1964). Patterns of attachment behavior shown by the infant in interaction with his mother. Merrill-Palmer Quarterly of Behavior and Development, 10(1), 51-58.

Ainsworth, M. D. S. (1967). Infancy in Uganda: Infant care and the growth of love.

Ainsworth, M. (1973). The Development of Infant-mother Attachment [w:] B. Caldwell, HN Ricciuti (red.), Review of Child Development Research, 1-94: Chicago: University of Chicago Press.

Ainsworth, M. D. S., Bowlby, J., Fry, M., \& Organization, W. H. (1965). Child care and the growth of love.

Arikan, G., \& Karanci, N. (2012). Attachment and coping as facilitators of posttraumatic growth in Turkish university students experiencing traumatic events. Journal of Trauma \& Dissociation, 13(2), 209-225.

Battistich, V., \& Hom, A. (1997). The relationship between students' sense of their school as a community and their involvement in problem behaviors. American journal of public health, 87(12), 1997-2001.

Booth, J. A., Farrell, A., \& Varano, S. P. (2008). Social control, serious delinquency, and risky behavior: A gendered analysis. Crime \& Delinquency.

Bowlby, J. (1958). The nature of the child's tie to his mother. The international journal of psycho-analysis, 39, 350.

Bowlby, J. (1969). Attachment and Loss: Attachment. V: Basic Books.

Bowlby, J. (1960a). Grief and mourning in infancy and early childhood. Psychoanalytic study of the child, 15(1), $9-52$.

Bowlby, J. (1960b). Separation anxiety. The international journal of psycho-analysis, 41, 89.

Brown, R., \& Evans, W. P. (2002). Extracurricular activity and ethnicity creating greater school connection among diverse student populations. Urban Education, 37(1), 41-58.

Bushway, S. D., Piquero, A. R., Broidy, L. M., Cauffman, E., \& Mazerolle, P. (2001). An empirical framework for studying desistance as a process. Criminology, 39(2), 491-516.

Catalano, R. F., \& Hawkins, J. D. (1996). A theory of antisocial behavior. Delinquency and crime: Current theories (1996), 149.

Cho, H., Hallfors, D. D., \& Sánchez, V. (2005). Evaluation of a high school peer group intervention for at-risk youth. Journal of abnormal child psychology, 33(3), 363-374.

Dumais, S. A. (2008). Cohort and gender differences in extracurricular participation: The relationship between activities, math achievement, and college expectations. Sociological Spectrum, 29(1), 72-100.

Dumais, S. A. (2009). The academic attitudes of American teenagers, 1990-2002: Cohort and gender effects on math achievement. Social Science Research, 38(4), 767-780.

Fredricks, J. A., \& Eccles, J. S. (2008). Participation in extracurricular activities in the middle school years: Are there developmental benefits for African American and European American youth? Journal of Youth and Adolescence, 37(9), 1029-1043.

Freud, S. (1920). The psychogenesis of a case of female homosexuality. International Journal of PsychoAnalysis, 1(2), 129-130.

Hawkins, J. D., Guo, J., Hill, K. G., Battin-Pearson, S., \& Abbott, R. D. (2001). Long-term effects of the Seattle Social Development Intervention on school bonding trajectories. Applied Developmental Science, 5(4), 225-236.

Huebner, A. J., \& Betts, S. C. (2002). Exploring the utility of social control theory for youth development issues of attachment, involvement, and gender. Youth \& Society, 34(2), 123-145.

Hirschi, T. (1969). A control theory of delinquency. Criminology theory: Selected classic readings, 289-305.

Hirschi, T. (2002). Causes of delinquency: Transaction publishers.

Loukas, A., Roalson, L. A., \& Herrera, D. E. (2010). School connectedness buffers the effects of negative family relations and poor effortful control on early adolescent conduct problems. Journal of research on adolescence, 20(1), 13-22.

Libbey, H. P. (2004). Measuring student relationships to school: Attachment, bonding, connectedness, and engagement. Journal of School Health, 74(7), 274-283.

Maddox, S. J., \& Prinz, R. J. (2003). School bonding in children and adolescents: Conceptualization, assessment, and associated variables. Clinical child and family psychology review, 6(1), 31-49.

O'Farrell, S. L., \& Morrison, G. M. (2003). A factor analysis exploring school bonding and related constructs among upper elementary students. The California School Psychologist, 8(1), 53-72.

Resnick, M. D., Bearman, P. S., Blum, R. W., Bauman, K. E., Harris, K. M., Jones, J., . . . Shew, M. (1997). Protecting adolescents from harm: findings from the National Longitudinal Study on Adolescent Health. Jama, 278(10), 823-832.

Schwartz, J. (2015). The Unacknowledged History of John Bowlby's Attachment Theory. British Journal of Psychotherapy, 31(2), 251-266.

Sciarra, D., \& Seirup, H. (2008). The multidimensionality of school engagement and math achievement among racial groups. Professional School Counseling, 11(4), 218-228. 
Slade, A. (1999). Attachment theory and research: Implications for the theory and practice of individual psychotherapy with adults.

Stewart, E. B. (2007). Individual and school structural effects on African American high school students' academic achievement. The High School Journal, 91(2), 16-34.

Wiatrowski, M. D., Griswold, D. B., \& Roberts, M. K. (1981). Social control theory and delinquency. American sociological review, 525-541.

Williams, J. H., Ayers, C. D., Abbott, R. D., Hawkins, J. D., \& Catalano, R. F. (1999). Racial differences in risk factors for delinquency and substance use among adolescents. Social Work Research, 23(4), 241-256.

Zaff, J. F., Moore, K. A., Papillo, A. R., \& Williams, S. (2003). Implications of extracurricular activity participation during adolescence on positive outcomes. Journal of Adolescent Research, 18(6), 599-630.

Zurbriggen, E. L., Gobin, R. L., \& Kaehler, L. A. (2012). Trauma, attachment, and intimate relationships. Journal of Trauma \& Dissociation, 13(2), 127-133. 